\title{
BMJ Open Protocol for a prospective longitudinal study investigating the participation and educational trajectories of Australian students with autism
}

\author{
Jacqueline Margaret Anne Roberts, ${ }^{1,2,3}$ Dawn Adams, ${ }^{1,2,3}$ Helen Heussler, ${ }^{4}$ \\ Deborah Keen, ${ }^{1,2,3}$ Jessica Paynter, ${ }^{3,5,6}$ David Trembath,, 3,6,7 \\ Marleen Westerveld, ${ }^{2,3,6,7}$ Katrina Williams ${ }^{8,9,10}$
}

To cite: Roberts JMA, Adams D, Heussler $\mathrm{H}$, et al. Protocol for a prospective longitudinal study investigating the participation and educational trajectories of Australian students with autism. BMJ Open 2018;8:e017082. doi:10.1136/ bmjopen-2017-017082

- Prepublication history for this paper is available online. To view these files, please visit the journal online (http://dx.doi. org/10.1136/bmjopen-2017017082).

Received 2 April 2017 Accepted 30 August 2017

Check for updates

For numbered affiliations see end of article.

\section{Correspondence to} Professor Jacqueline Margaret Anne Roberts;

j.roberts@griffith.edu.au

\section{ABSTRACT}

Introduction Autism is associated with high cost to individuals, families, communities and government. Understanding educational and participation trajectories during the school years, and factors influencing these, is fundamental to reducing financial and personal costs. The primary aim of this study is to document the trajectories of Australian students with autism during their education. The secondary aim is to examine personal (eg, student skills) and environmental (eg, school setting) factors associated with differing trajectories and outcomes.

Methods and analysis The cross-sequential longitudinal study will recruit two cohorts of 120 parents/caregivers of children with autism. Cohort 1 aged between 4 and 5 years and cohort 2 between 9 and 10 years to start the study. Information will be gathered from parents, teachers and school principals at six annual time points (T1 to T6). Parents will be emailed a link to an online initial questionnaire (T1) and then contacted annually and asked to complete either an extended questionnaire (T3, T5 and T6) or an abbreviated questionnaire (T2, T4). Where consent is given, the child's current school will be contacted annually (T1 to T6) and teacher and school principal asked to complete questionnaires about the child and school. Parent and school questionnaires are comprised of questions about demographic and school factors that could influence trajectories and a battery of developmental and behavioural assessment tools designed to assess educational and participation trajectories and outcomes. Surveys will provide longitudinal data on educational and participation trajectories for children and adolescents with autism. In addition cross-sectional comparisons (within or between age groups) at each time point and cohort effects will be explored. Ethics and dissemination Ethics approvals have been granted for this study by all recruiting sites and universities in the project. Study findings will inform policy and practice to promote successful inclusion and participation of children with autism in education. Results will be disseminated through journal publication, conference and seminar presentation.

\section{INTRODUCTION}

Autism spectrum disorder (ASD), herein referred to as autism, is a lifelong neurodevelopmental condition affecting at least 1 in 100 children $^{1}$ characterised by impairments in

\section{Strengths and limitations of this study}

- The study will add to our understanding of the effect of characteristics of autism, family factors, school factors and interventions on educational and personal outcomes for children and young people with autism.

- Enable the development and tailoring of appropriate interventions to improve outcomes.

- Inform policy development in Health and Education in relation to service development and provision for autism communities.

- The participants may be biased towards those with sufficient time, motivation and internet access to complete extensive online surveys over 6 years.

- Information collected is all via parent/teacher report.

social communication and behaviour. Autism is a spectrum disorder; children, adolescents and adults present with differing individual strengths, needs and preferences for services and supports. Autism is associated with high cost to individuals, families, communities and government, ${ }^{23}$ highlighting the importance of understanding the nature of autism and optimal supports.

It is important to understand the impact of difficulties or disability on function and participation. Application of the International Classification of Functioning, Disability and Health $)^{4}$ framework allows us to assess the environmental impacts of characteristics of autism on daily life. Although this approach has been widely adopted in other disabilities, it has only been relatively recently integrated into studies and thinking in autism. ${ }^{56}$

There is growing evidence that learning in conventional educational environments presents a substantial challenge for most individuals with autism. The most recent survey of educational needs in children with autism 
in Australia reported that $86 \%$ are 'having difficulty' at school, with the majority of difficulties being in social cognitive and communication domains. ${ }^{7}$ Although these difficulties are recognised both academically and clinically as potential barriers to learning, the influence of each of these factors on educational participation and achievement is yet to be explored. This is important, as almost all $(95 \%)$ children with autism experience some kind of educational restriction. ${ }^{8}$

The long-term impact of not affording individuals with autism appropriate educational supports at an early age is becoming increasingly apparent. Many adults with autism are unemployed, experience mental illness, have reduced independence ${ }^{9}$ and are disenfranchised from mainstream society. A recent systematic review of adults with autism classed outcomes in social integration and independence as 'poor' or 'very poor', with $50 \%$ or more of individuals remaining fully or largely dependent on parents or carers and requiring significant support for education, living arrangements and employment. ${ }^{10}$ Unemployment is higher in those with autism than in those with speechlanguage impairments and intellectual disability, indicating that the combination of social, communication and behaviour challenges that are part of autism places these individuals at heightened risk for poor community participation. ${ }^{8}$

While we have some understanding of the long-term outcomes for adults with autism, ${ }^{10-12}$ we know little about the experiences and trajectories of students with autism during their school years, and factors that influence these. Despite the documented difficulties that children with autism experience in school and the well-recognised need to improve educational outcomes for students with autism, ${ }^{13}$ there is limited information about participation in school, the educational trajectories and the impact of educational experiences on educational outcomes. This limits the capacity of parents, teachers, allied health professionals and others to positively influence growth in this critical developmental and educational period. It is also unknown which child, family and environmental factors may influence these trajectories over time. Characteristics of autism potentially affecting education include both communication and social characteristics and repetitive behaviours and restricted interests. Information about educational trajectories and outcomes and the way these interact with child characteristics, including later developing characteristics such as mental health disorders, is needed to enable tailoring of interventions and educational approaches for individual children and young people with autism and their families during their schooling. Such information is also needed to understand the experience of children with autism in the educational environment and explore the impact of these experiences on their development, participation and social relating. Taken together, there is a clear need for further research into the potential relationships between characteristics of autism, the environment and outcomes, particularly educational outcomes, both academic (eg, literacy) and personal (eg, peer relationships).
Young people with autism have more difficulties with important transitions (eg, between preschool and primary school, primary to high school), than their peers ${ }^{14} 15$ which means they are likely to start school at a disadvantage compared with their typical peers. Longitudinal studies during time periods where major transitions occur have the potential to increase our understanding of interactions between key characteristics of autism, environmental factors, any interventions or supports provided during these challenging times and outcomes.

The heterogeneity of individuals with autism and their communities (eg, caregivers, teachers, allied health clinicians, school executive) and the wide variety of interventions that individuals access (evidence based and otherwise), means it is difficult to draw conclusions from cross-sectional designs, even with large participant samples. In contrast, the cross-sequential longitudinal research design we describe in this paper will reduce these limitations. This is particularly relevant in educational settings, where factors such as school engagement and participation can be observed in a cohort over time and compared with outcomes, presently an underdocumented and under-researched area.

\section{Study aims}

The primary aim of the Longitudinal Study of Australian Students with Autism (LASA), is to document the educational and participation trajectories and outcomes of Australian students with autism over a 6-year period. The secondary aim is to examine personal (eg, student skills, caregiver) and environmental (eg, school setting, community supports) factors associated with varied trajectories and outcomes.

\section{METHODS AND ANALYSES \\ Study design}

The LASA is a cross-sequential, prospective, longitudinal, quantitative study. Data will be collected annually over 6years focussing on educational and participation outcomes from two cohorts of children with autism, cohort 1 aged 4-5 years and cohort 2 aged 9-10 years, at time of recruitment. The age ranges were chosen to ensure that data collection occurred over two critical transition periods; starting school and moving from primary to high school. Caregivers and education professionals will provide information annually about progress in education and participation, as well as factors such as adaptive behaviour, hypothesised in the research literature to be associated with differing trajectories and outcomes. The project is managed by the LASA partners advisory group consisting of the primary coapplicants and is chaired by the principal investigator (name deleted).

\section{Study funding}

The study is funded by Cooperative Research Centre for the Living with Autism (Autism CRC), ${ }^{16}$ a federally 
funded programme to support industry-led collaborations between industry, researchers and the community. ${ }^{16}$ The funders of this study advocate inclusive research practices process and active inclusion of the autistic community in the research is a condition of funding. To this end, autistic people are involved in the assessments of all grant applications, shape key research questions, review final reports for the project. Further to this, the Autism CRC has established the Autism CRC Research Academy to build the capacity for coproduction/peer research within the autistic and research communities in Australia. Details of the Autism CRC policies and practices relating to inclusive research are available from their website (https://www.autismcrc.com.au/ connect-hub/ resources/inclusive-research-practice). Autistic people have also been encouraged to apply for higher degree research (Masters Research and PhD) including two PhD scholarships associated with the longitudinal study.

\section{Study population}

Participants will be recruited across all states and territories in Australia, which has a population of approximately 23 million people, including nearly 4 million school-aged children. ${ }^{17}$ With a conservative estimated prevalence of 1 in 100 children, the estimated number of all school-aged children with autism at this time is over 35000 .

The primary participant group will be caregivers of children with autism aged 4-5 years or 9-10 years at time of recruitment. Each child must have received a clinical diagnosis of autism by health professionals in the community. Parents will be asked to provide a copy of their child's diagnostic assessment report. The Social Communication Questionnaire $(\mathrm{SCQ})^{18}$ is included in the parent questionnaire to verify the child's diagnosis. Children with additional medical diagnoses (eg, seizure disorders, intellectual disability) will be included to ensure a study sample reflecting the population of young people with autism. Caregivers will be asked to complete questionnaires and participate via phone conversations with the research team. These tasks assume skills in spoken and written English, but no exclusion criteria will be adopted in order to recruit a sample that reflects the heterogeneity of the population.

The second key participant group is educational professionals, namely principals and teachers currently working with each child with autism in formal school or distance education settings, who consent to participate in the study. No exclusionary criteria will be applied.

\section{Participant selection and recruitment}

Parent/caregiver participants will be recruited nationally from organisations such as child development units and early intervention services, state autism organisations, parent support groups, autism advocacy groups and through websites, mailing lists and internet groups.

Parents/caregivers will be asked to register to participate in the study through an internet link. Parents who register, will be contacted by a research team member and if their child is eligible and they agree to participate, they will be sent an online parent/caregiver questionnaire.

If parent consent is given, the principal of their child's school will be contacted and asked to complete a questionnaire about the school. The principal will also be asked to consent to the research team contacting the child's teacher. If children have several teachers, the principal will be asked to select the teacher who has the best knowledge of the child. Once this consent is given, the child's teacher will be contacted and asked to complete an online questionnaire about the child's progress and participation at school.

\section{Data collection procedure}

Parents will be asked to complete online questionnaires annually for 6 years, comprising six time points (T1 to T6). Following recruitment, parents will be emailed a link to an online initial questionnaire (T1). Parents will then be contacted annually and asked to complete either an extended questionnaire (at T3, T5 and T6) or an abbreviated questionnaire (at T2, T4). Parents will also be contacted annually and asked to provide educational/school or assessment reports (diagnostic reports in particular) and current school contact information. The recruitment goal for the study is 120 participants in each cohort.

Where consent is given, the child's current school will be contacted annually and both the teacher and school principal will be asked to complete online questionnaires about the child or school respectively (T1 to T6). At each time point, parents, teachers and principals will be given 1 month to complete the questionnaire. During that period, they may stop and start the questionnaire as many times as they like with responses saved online. Participants who do not complete the questionnaires in that time will receive reminders via email and/or a phone call from the participant coordinator to offer assistance and confirm their willingness to continue in the study.

\section{Research measures}

A battery of developmental and behavioural assessment tools designed to assess educational and participation trajectories and outcomes, along with theoretically driven predictors of these, was selected following a review of the literature. The length of the questionnaire was monitored so as to minimise participant burden, with the abbreviated questionnaire (at T2 and T4) taking approximately $30 \mathrm{~min}$ to complete and the extended questionnaire (at $\mathrm{T} 1, \mathrm{~T} 3, \mathrm{~T} 5, \mathrm{~T} 6)$ taking approximately 2 hours to complete.

An overview of assessments for caregivers (including detail on their reliability and validity), and the time points at which they will be collected, is provided in table 1. An overview of assessments for schools (principals and teachers) is provided in table 2. The parents will complete questionnaires focussing on demographics, the primary outcome variable (child participation) and adaptive behaviour at each time point. The secondary outcomes, academic competence and family outcomes, 


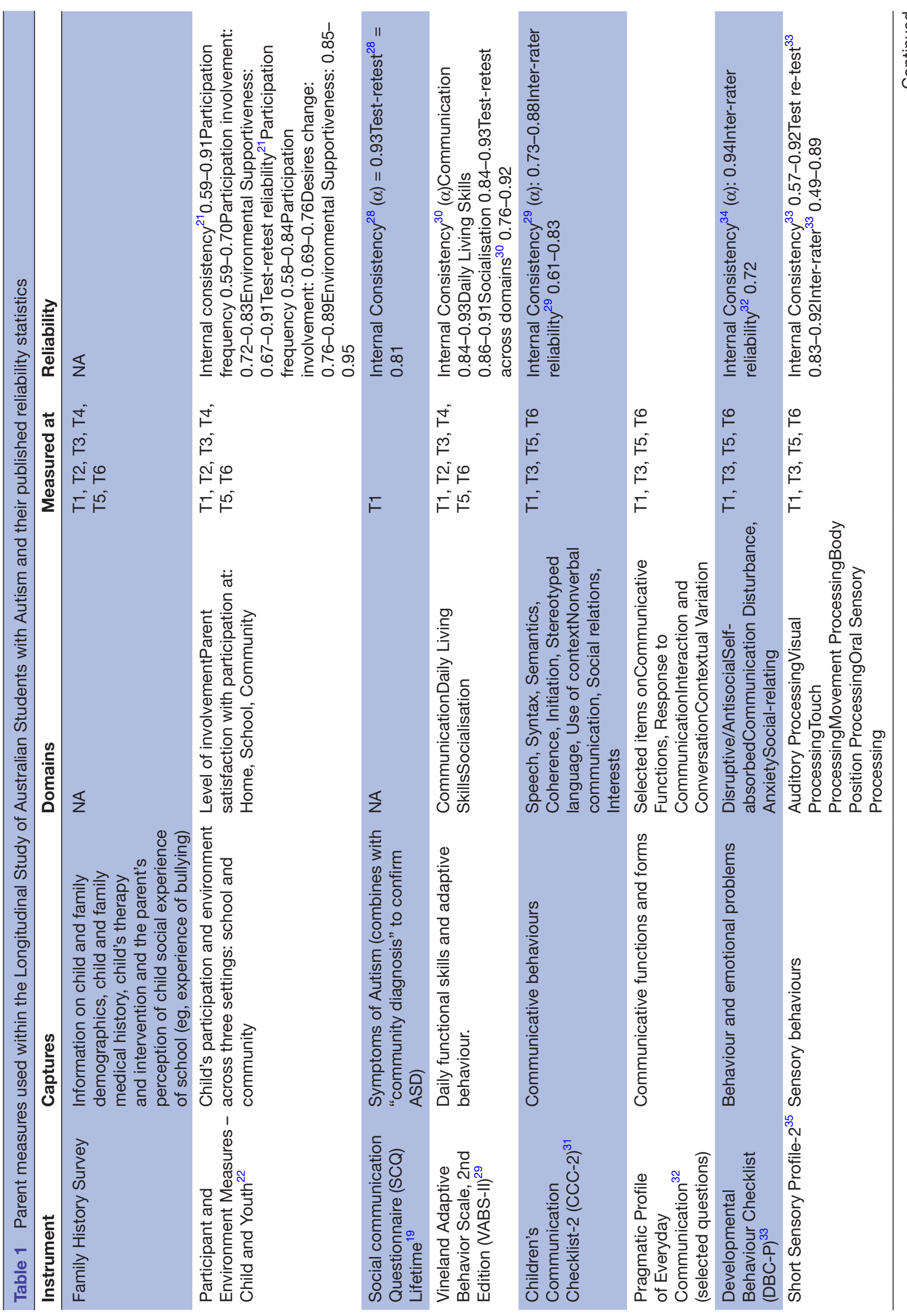

D 


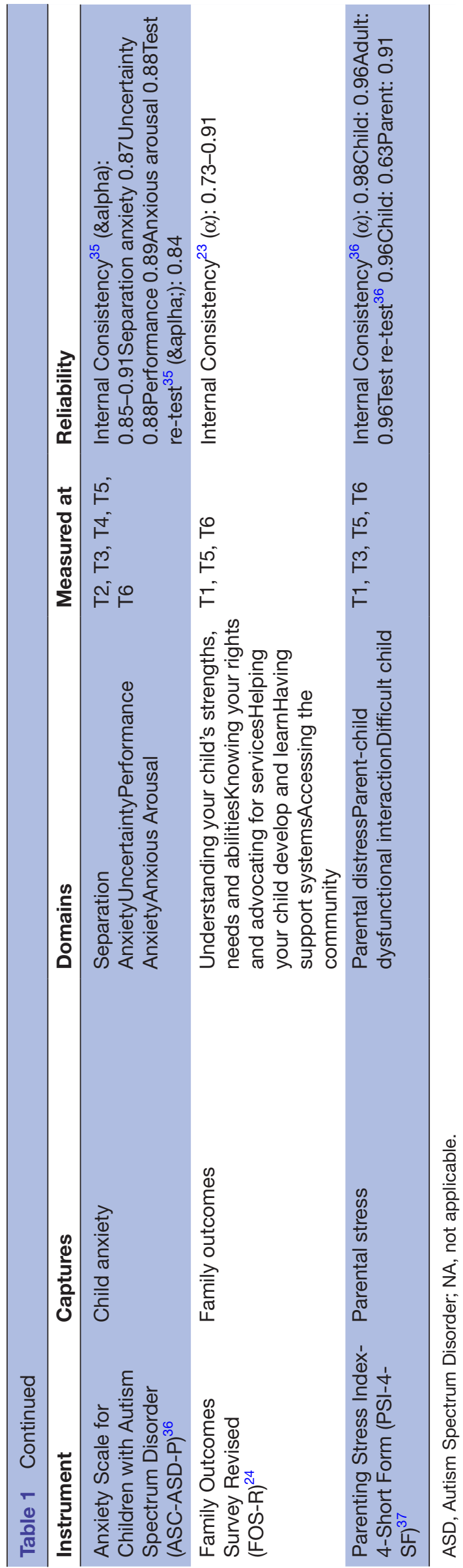

and other explanatory factors will be measured at T1, T3, T5 and T6. These include measures of communication, sensory characteristics, behavioural and emotional difficulties, anxiety and parent stress.

The questionnaire pack for teachers will consist of a questionnaire compiled using questions from the National Longitudinal Transition Study-2, ${ }^{19}$ US Department of Education and other sources, including the Longitudinal Study of Australian Children. ${ }^{20}$ This focuses on gathering information on the available support for transition to and within their school, use of Individual Education Plans, accommodations for standardised tests, social skills support, a standardised questionnaire on academic functioning for their student (compared with their peers) and a standardised questionnaire designed to gather information about the student's emotional, behavioural and social profile. Finally, the principal will be asked to complete a purpose-designed questionnaire about location, size and type of school (mainstream, specialist, special), exclusion and attendance rates and whole-school and individualised programmes or approaches for children with autism in place in their school. Copies of the purpose-designed questionnaires are available via email from the corresponding author.

\section{Primary outcome measure}

The primary outcome is a measure of child participation, the Participation and Environment Measure-Child and Youth $^{21}$ (PEM-CY), completed at each data collection point. This was selected as it measures a child's participation and environment across three settings: home (10 items), school (five items) and community (10 items). For each item, parents report how often their child participates in the activity (never (0) to daily (7)), how involved the child is in the activity (minimally involved (1) to very involved (5)) and whether the parent desires change in their child's participation in the activity. If parents state that they would like a change, they are asked more about this change in terms of frequency (to do it more or less often), involvement (be more or less involved) or if they would like their child involved in a broader range of activities within this category. The PEM-CY is suitable for children aged 5-17 years and has been shown to be reliable, with good strong internal consistency and good interrater reliability (detailed in table 1 ).

\section{Secondary outcome measures}

Secondary outcomes are a measure of academic competence $^{22}$ (Academic Competence Evaluation Scales; ACES) and the Family Outcomes Survey Revised (FOS-R) ${ }^{23}$

The ACES ${ }^{22}$ will be administered at each data collection point. It contains 73 questions that assess the academic functioning of students, grades K-12. It measures academic skills (33 items) (reading/language arts, mathematics, critical thinking) and academic enablers (40 items) (interpersonal skills, engagement, motivation and study skills). Teachers rate their student's academic skills relative to school expectations on a five-point scale ranging from far below (1) to far above (5) and how important the skill is for academic 


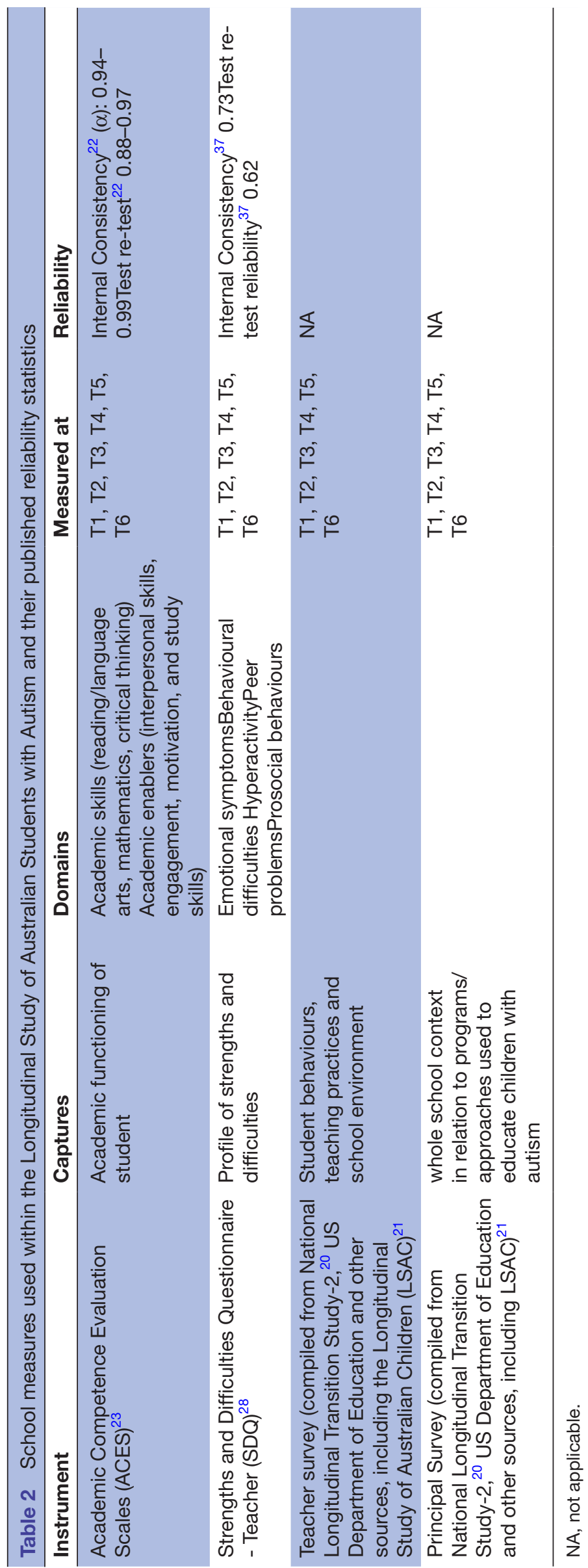

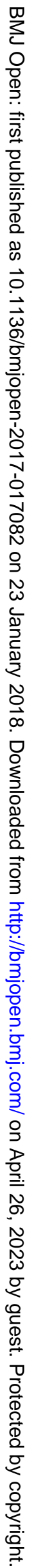


success in the classroom on a three-point scale ranging from not important (1) to critical (3). There is also a N/O option for each question if the teacher has not had the opportunity to observe the skill. For the academic enablers teachers rate how frequently their student shows the behaviours on a fivepoint scale, ranging from never (1) to almost always (5) and their importance in the classroom on a three-point scale, not important (1) to critical (3). There is also a N/O option for each question if the teacher has not had the opportunity to observe the skill. A raw score is obtained for each of the academic skill areas and the academic enablers areas and is interpreted in relation to the child's age and grade at school. The manual provides normative data for children with and without learning disabilities.

The FOS-R ${ }^{24}$ has two sections. Section A will be administered at T1, T5 and T6 and section B at T1 only. Section A consists of 24 items and focuses on five family outcomes: (1) understanding your child's strengths, needs and abilities; (2) knowing your rights and advocating for services; (3) helping your child develop and learn; (4) having support systems and (5) accessing the community. Section A assesses the extent to which families have achieved these outcomes on a five-point scale ranging from (1) not at all to (5) completely. Section B consists of 17 items and focuses on the three helpfulness indicators of knowing your rights; communicating your child's needs and helping your child develop and learn. Section B assesses the helpfulness of early intervention on a five-point scale ranging from (1) not at all helpful to (5) extremely helpful.

\section{Explanatory factors}

In order to explain the educational and participation trajectories of children with autism, factors potentially interacting with the outcomes are also examined. These factors were selected based on a thorough literature review and are explained below, with details of each measure provided in table 1 . These factors can be categorised as child, family and educational environment factors. Child factors include behavioural and emotional difficulties, communication skills, adaptive behaviour, sensory behaviours, child anxiety, parental stress and family demographics will also be assessed. Educational environment will be documented through the principal, teacher and parent surveys.

\section{Data collection}

The online questionnaires will be developed in the online survey system, Qualtrics. An internet link to the questionnaire will be sent to each participant via email which contains a personal ID that links the child participant with responses collected from their parent/caregiver, their teacher and school principal. The responses will be stored in a password protected Qualtrics database accessible by two research team members. The project coordinator is responsible for cleaning and removing personally identifiable information from the data. The data will only be accessible to the project team and is stored in line with National Health Medical Research Council $^{24}$ best practice.

\section{Feedback to families and school}

Parents will receive a written summary of their child's annual survey results. If parents wish to receive formal scored reports for the standardised child assessments included in the questionnaire, they will be required to complete a Client Consent to Share Information Form B. Once consent is given, the LASA research team will share the scored reports with the child's health or allied health professional nominated by the parent. This procedure is consistent with ethical mandates ${ }^{25}$ designed to ensure that information is not released, that is, potentially distressing to parents or requires interpretation.

Caregivers, teachers and principals will receive updates about the study through an annual newsletter and access to social media pages of the Autism Centre for Excellence. Throughout the study, results will be presented in aggregate format only and presented in an accessible format for a lay audience. The Autism Centre for Excellence social media site will also keep participants informed about what is new in ASDs and evidence-based strategies.

\section{Data analysis}

The data collected in the study provides longitudinal data on educational and participation trajectories for children with autism. However, it is designed with sample sizes large enough to allow for cross-sectional comparisons (within or between age groups) at each time point. Cohort effects can also be explored by comparing data from when both groups are 9-10 years old (T1 for cohort 2 and T6 for cohort 1). Missing data will be examined and if appropriate, imputation implemented (the exact method of which will depend on the missing data). As there is likely to be less than $100 \%$ retention at each follow-up, potential bias in retainment will be assessed by comparing baseline characteristics (including severity of ASD, parent self-reported stress and socioeconomic status) of retained and non-retained participants using model diagnostics.

To document the participants' educational and participation trajectories and outcomes (primary aim), descriptive statistics (frequencies, means, medians and SD) pertaining to the outcome measures and putative explanatory factors will be presented for each cohort at each time point.

Group comparisons on cross-sectional data, such as comparisons between the younger and older groups or between smaller subgroups, will be performed using independent samples t-tests or equivalent non-parametric tests if the data are not normally distributed. Consideration will be given to error with the use of multiple comparisons. Using independent t-tests, with $\alpha=0.05, \beta=0.80$ and medium effect size of 0.5 a sample of 102 participants is required. ${ }^{26}$ Our target sample size of 120 children in each cohort allows for an attrition rate of approximately $15 \%$ over the course of the study. Cross-sectional analysis of standardised scores will also be performed using t-test or multivariate analysis of variance and mediating or moderating factors explored using regression models.

Multiple regression will be used to examine personal and environmental factors associated with differing trajectories 
and outcomes (secondary aim). The interaction or influence of the explanatory factors, such as level of adaptive behaviour (measured by the Vineland Adaptive Behavior Scale (VABS)), severity of Autism Symptoms (measured by the SCQ) or sensory behaviours (measured by the Short Sensory Profile-2 (SSP-2)) will be explored within these regression models.

For the longitudinal analyses, a Bayesian-mixed effects model is planned. Using this approach, missing values can be treated as another variable in the modelling process. As such, there are a number of approaches available to analysing longitudinal results with missing data. Documentation of the participants' educational and participation trajectories and outcomes (primary aim) will be assessed on the PEM-CY, with through posterior predictive profile for the measure being estimated based on the significant variables. Personal and environmental factors associated with differing trajectories and outcomes (secondary aim) will also be examined in this modelling framework. The interaction or influence of the explanatory factors, such as level of adaptive behaviour (measured by the VABS), severity of Autism Symptoms (measured by the SCQ) or sensory behaviours (measured by the SSP-2) will also be considered.

\section{Methodological considerations \\ Questionnaire data}

The format of this study (data collection through questionnaires) allows for recruitment of a reasonably large sample of children and families. However, it is acknowledged that all of the information for this study is collected through questionnaires and interviews, without meeting the child or family. This means that it is not possible for the data to include direct measures of ability (such as intellectual ability) or to complete formal assessments ${ }^{27}$ (such as the ADOS). To address this issue, all parents will be asked to complete a validated autism screening questionnaire (SCQ) and are required to send in copies of their child's diagnostic reports. Parents will also be asked to send in reports of any additional assessments, particularly cognitive assessments.

\section{Bias in recruitment}

The nature of the present study requires a significant commitment from participants and where applicable, their teachers and principals. Parents are asked to complete six online questionnaires, four of which will take approximately 2 hours to complete. This may influence the recruitment procedure and may, over the duration of the study, reduce completion rates. It is therefore possible that there will be a recruitment bias (ie, families who can afford the time to complete the questionnaire and/or who have ready access to a computer with internet access). It may also be that the research may only attract parents that have an interest in the focus of this study. To address this issue, efforts will be directed towards recruiting from a range of sources and in providing parents with the ability to $\log$ in and out of their questionnaire completion site so they can complete the questionnaire pack in small sections over 1 month. Demographic information alongside information about challenging behaviour (from the Developmental Behaviour Checklist) and parental stress (from the Parenting Stress Index-Short Form) will be compared between those who complete and those who leave the study in order to identify factors that may have contributed to non-completion.

\section{Ethics and dissemination}

The study has received ethical approval from all recruiting sites and universities involved in the project (see list below). All parents will provide consent for their child to join the study. Parents can also choose whether to give consent for teacher and principal questionnaires to be collected. Results from standardised questionnaires can be shared with nominated health professionals if requested by the consenting caregiver.

It is not anticipated that participants will be subject to any risks during this study. It is possible that parents may become distressed when communicating about their child's autism or associated strengths and difficulties. The survey is designed to end with questions for parents about their child's strengths and interests to end on a positive note. All parents are provided with the contact details of the project administrator (who can direct the parent to an appropriate clinically trained member of the research team) to discuss the questionnaire. The research team are willing and able to refer parents to a range of specialised support services if this is deemed necessary or helpful.

Participant information will be securely stored electronically or in the project office. Questionnaires are completed online and personal identifiable information received (such as copies of diagnostic reports) will be stored in a locked filing cabinet. Once downloaded from the online database, all participant data will be anonymised by allocating each participant with an ID number. De-identified participant data will be saved on a password-protected secure computer drive which only members of the research team have access to. Participants' personal identifiable data will be stored in a separate location to de-identified participant data. Identifiable data will only be accessible to the project manager and the project leader.

Throughout the course of the study and once the longitudinal data collection is complete, results (de-identified and primarily aggregated) will be published in peer-reviewed mainstream and specialist journals. Presentations of study findings will be made at relevant research conferences, local research symposiums and seminars for professionals working with children with autism and those in autism research. In addition, local stakeholders (such as autism schools and non-governmentorganisations) will be consulted in the development of methods for dissemination they find effective in reaching families of children with autism. 


\section{Significance and outlook}

This study will make an important contribution to the very limited longitudinal data on the pattern and effects of participation in children with autism. The design allows for annual cross-sectional comparisons, within subject comparisons, exploration of cohort effects (by comparing data from both groups at 9-10years) and the 6 -year longitudinal analysis. Collecting data and information from a range of sources (parents, teachers and principals) allows for a holistic description of progress and change across the duration of the study.

Study results will inform clinicians, children and their families about the factors that promote or reduce participation and educational outcomes and therefore help to identify children who are most likely to benefit from specific interventions. It will also be important data for educators, who will be able to proactively monitor factors that put children with autism at risk of not achieving their full educational potential.

The study team is also focused on developing capacity of early career researchers through mentorship and supervision. It will provide data for a number of $\mathrm{PhD}$, Masters and honours students who often cannot gain experience with longitudinal datasets due to time constraints and allow them to develop the methodological and statistical expertise required for such methods. This is particularly important given the identified need for longitudinal studies in a large number of health, educational and developmental areas.

\section{SUMMARY AND CONCLUSION}

Autism is an increasingly common condition. Although profiles and presentations are highly variable, a consistent finding is poor life outcomes for adults with autism across domains such as employment and independent living. Given that the primary aim of education is the preparation of children and young people for adult life, it could be argued that the educational process is not achieving this aim for the majority of young people with autism. In this study, data will be collected at key developmental periods including times of major transition (school entry and transition from primary to high school) and factors critical to participation and educational achievement will be explored and documented. Understanding these trajectories and the factors that influence them will assist clinicians working with individual children and their families to describe expected outcome and necessary services and supports, and planning to improve educational environments.

\section{Author affiliations}

${ }^{1}$ Autism Centre of Excellence, School of Education and Professional Studies, Griffith Univeristy, Brisbane, Queensland, Australia

${ }^{2}$ Griffith Institute for Educational Research, Griffith University, Brisbane, Queensland, Australia

${ }^{3}$ Cooperative Research Centre for Living with Autism (Autism CRC), Brisbane, Australia

${ }^{4}$ Children's Health Queensland, Mater Research Institute, Brisbane, Queensland, Australia

${ }^{5}$ School of Applied Psychology, Griffith University, Southport, Queensland, Australia

${ }^{6}$ Menzies Health Institute, Gold Coast, Queensland, Australia
${ }^{7}$ School of Allied Health Sciences, Griffith University, Gold Coast, Queensland, Australia

${ }^{8}$ Murdoch Children's Research Institute, Australia

${ }^{9}$ Department of Paediatrics, University of Melbourne, Melbourne, Victoria, Australia ${ }^{10}$ Department of Neurodevelopment and Disability, The Royal Children's Hospital, Melbourne, Australia

Acknowledgements The authors would like to acknowledge input to the project from the LASA partners group, the LASA project manager, Robyn Garland, her predecessor Greta Ridley and the children, their families and schools participating in this study.

Contributors JMAR conceptualised and codesigned the study, developed the first draft of the manuscript, reviewed and revised the manuscript, and finalised the manuscript for publication. DA drafted the final manuscript, reviewed and revised the manuscript, and approved the final manuscript. HH contributed to the design of the study and review of the manuscript and approved the final manuscript. DK, DT and KW co-designed the study, assisted with manuscript drafting, reviewed and revised the manuscript, and approved the final manuscript. JP contributed to the design of the study, assisted with manuscript drafting and review of the manuscript, and approved the final manuscript. MW contributed to the design of the study, assisted with manuscript drafting, read and approved the final manuscript.

Funding The authors acknowledge the financial support of the Cooperative Research Centre for Living with Autism (Autism CRC), established and supported under the Australian Government's Cooperative Research Centres Program.

\section{Competing interests None declared.}

Patient consent Parental/guardian consent obtained.

Ethics approval Mater Health Services HREC Clearance Number HREC/14/ MHS/122 (15 July 2014). Children's Health Queensland Hospital and Health Service SSR reference number SSA/15/QRCH/23 (26 February 2015). Griffith University HREC Clearance Number EDN/76/14/HREC (22 July 2014). Sydney Children's Hospital Network HREC Clearance Number HREC/14/SCHN/253 (10 September 2014). Royal Children's Hospital Melbourne HREC Clearance Number 34213 A (25 September 2014).

Provenance and peer review Not commissioned; externally peer reviewed.

Open Access This is an Open Access article distributed in accordance with the Creative Commons Attribution Non Commercial (CC BY-NC 4.0) license, which permits others to distribute, remix, adapt, build upon this work non-commercially, and license their derivative works on different terms, provided the original work is properly cited and the use is non-commercial. See: http://creativecommons.org/ licenses/by-nc/4.0/

(C) Article author(s) (or their employer(s) unless otherwise stated in the text of the article) 2018. All rights reserved. No commercial use is permitted unless otherwise expressly granted.

\section{REFERENCES}

1. Centers for Disease Control and Prevention (CDC). Prevalence of autism spectrum disorder among children aged 8 years - autism and developmental disabilities monitoring network, 11 sites, United States, 2010. MMWR Surveill Summ 2014;63:1-22.

2. Horlin $\mathrm{C}$, Falkmer M, Parsons $\mathrm{R}$, et al. The cost of autism spectrum disorders. PLoS One 2014;9:e106552.

3. Synergies Economic Consulting. Economic costs of autism spectrum disorder in Australia: updated study. Brisbane: Synergies Economic Consulting, 2011.

4. World Health Organization. International Classification of Functioning, Disability and Health. Geneva: World Health Organization, 2001.

5. Bölte S, de Schipper E, Robison JE, et al. Classification of functioning and impairment: the development of ICF core sets for autism spectrum disorder. Autism Res 2014;7:167-72.

6. de Schipper E, Lundequist A, Coghill D, et al. Ability and disability in autism spectrum disorder: a systematic literature review employing the International Classification of Functioning, Disability and HealthChildren and Youth Version. Autism Res 2015;8:782-94.

7. ABS Survey of Disability, 2012. http://www.abs.gov.au/AUSSTATS/ abs@.nsf/DetailsPage/4430.02012

8. 4428.0- Autism in Australia, Australian Bureau of Statistics, 2012. http://www.abs.gov.au/ausstats/abs@.nsf/Latestproducts/4428. OMain\%20Features52012?opendocument\&tabname=Summary\& prodno $=4428$. 0 \&issue $=2012 \&$ num $=\&$ view $=$ 
9. Moss P, Howlin P, Savage S, et al. Self and informant reports of mental health difficulties among adults with autism findings from a long-term follow-up study. Autism 2015;19:832-41.

10. Magiati I, Tay XW, Howlin P. Cognitive, language, social and behavioural outcomes in adults with autism spectrum disorders: a systematic review of longitudinal follow-up studies in adulthood. Clin Psychol Rev 2014;34:73-86.

11. Fein D, Barton M, Eigsti IM, et al. Optimal outcome in individuals with a history of autism. J Child Psychol Psychiatry 2013;54:195-205.

12. Howlin P, Savage S, Moss P, et al. Cognitive and language skills in adults with autism: a 40-year follow-up. J Child Psychol Psychiatry 2014;55:49-58.

13. Roberts J, Simpson K. A review of research into stakeholder perspectives on inclusion of students with autism in mainstream schools. Int J Incl Educ 2016;20:1-13.

14. Prior M, Roberts JMA, Rodger S, et al. A review of the research to identify the most effective models of practice in early intervention of children with autism spectrum disorders. Australian Government Department of Families, Housing, Community Services and Indigenous Affairs. Australia, 2011. http://www.fahcsia.gov.au/sites/ default/files/documents/09_2012/review_of_the_research_report_ 2011_0.pdf.

15. Roberts JMA, Williams K. Autism spectrum disorder: Evidencebased/evidence-informed good practice for supports provided to preschool children, their families and carers. Report prepared for the National Disability Insurance Agency (NDIA). 2016.

16. Autism CRC, 2016. http://www.autismcrc.com.au/about-crcs

17. 4221.0 - Schools, Australia, 2015. Australian Bureau of Statistics, 2015. http://www.abs.gov.au/ausstats/abs@.nsf/mf/4221.0

18. Rutter M, Bailey MD, Lord C. The Social Communication Questionnaire (SCQ). Los Angeles, CA: Western Psychological Services, 2003.

19. National Longitudinal Transition Study-2, US Department of Education US Department of Education. Welcome to NLTS2. http:// www.nlts2.org/index.html

20. Longitudinal Study of Australian Children (LSAC) Growing up in Australia: the longitudinal study of Australian children (LSAC). http:// growingupinaustralia.gov.au/

21. Coster W, Bedell G, Law M, et al. Psychometric evaluation of the Participation and Environment Measure for Children and Youth. Dev Med Child Neurol 2011;53:1030-7.
22. DiPerna JC, Elliott SN. Academic competence evaluation scales. San Antonio: the Psychological Corporation, 2000.

23. Bailey DB, Raspa M, Olmsted MG, et al. Development and psychometric validation of the family outcomes survey-revised. J Early Interv 2011;33:6-23.

24. National Statement on Ethical Conduct in Human Research. The National Health and Medical Research Council, the Australian Research Council and the Australian Vice-Chancellors' Committee. Canberra: Commonwealth of Australia, 2007.

25. Australian Psychological Society. Code of ethics. Melbourne, Vic: Author, 2012.

26. Faul F, Erdfelder E, Lang AG, et al. G*Power 3: a flexible statistical power analysis program for the social, behavioral, and biomedical sciences. Behav Res Methods 2007;39:175-91.

27. Lord C, Rutter M, Pamela C, et al. ADOS: Autism diagnostic observation schedule. Hogrefe, 2008.

28. Skuse DH, Mandy WP, Scourfield J. Measuring autistic traits: heritability, reliability and validity of the Social and Communication Disorders Checklist. Br J Psychiatry 2005;187:568-72.

29. Bishop DVM. Children's Communication Checklist-2 (CCC-2). San Antonio, TX: Pearson, 2006.

30. Sparrow SS, Cicchetti DV, Balla DA. Vineland II: Vineland Adaptive Behavior Scales. Bloomington, MN: Pearson, 2005.

31. Dewart H, Summers S. The Pragmatics Profile of Early Communication Skills. London: Nfer-Nelson, 1995.

32. Einfeld SL, Tonge BJ. Manual for the Developmental Behaviour Checklist. Clayton, Melbourne and Sydney Monash: University for Developmental Psychiatry and School of Psychiatry, University of New South Wales, 1992.

33. Dunn W. Sensory Profile 2. Bloomington, MN, USA: Pearson Psychcorp, 2014.

34. Tonge BJ, Brereton AV, Gray KM, et al. Behavioural and Emotional Disturbance in High-Functioning Autism and Asperger Syndrome. Autism 1999;3:117-30.

35. Rodgers J, Wigham S, McConachie H, et al. Development of the anxiety scale for children with autism spectrum disorder (ASC-ASD). Autism Res 2016;9:1205-15.

36. Abidin RR. Parenting Stress Index Professional Manual. 4th ed. Lutz, FL: PAR, 2012.

37. Goodman R. The Strengths and Difficulties Questionnaire: a research note. J Child Psychol Psychiatry 1997;38:581-6. 